\title{
Imperfect Capital Mobility in an Open Economy Model of Capital Accumulation
}

\author{
Vladimir Klyuev
}




\title{
IMF Working Paper
}

\author{
IMF Institute
}

\section{Imperfect Capital Mobility in an Open Economy Model of Capital Accumulation}

\author{
Prepared by Vladimir Klyuev ${ }^{1}$ \\ Authorized for distribution by Eric V. Clifton
}

February 2004

\begin{abstract}

\section{This Working Paper should not be reported as representing the views of the IMF.} The views expressed in this Working Paper are those of the author(s) and do not necessarily represent those of the IMF or IMF policy. Working Papers describe research in progress by the author(s) and are published to elicit comments and to further debate.
\end{abstract}

This paper introduces a tractable capital market friction mechanism that allows a break of the parity between domestic and external interest rates and generates a gradual evolution of capital stock and other macroeconomic variables - in contrast to the instantaneous convergence found in models with interest rate parity. The friction, derived from explicit microfoundations, is such that the cost of new loans is an increasing function of net borrowing. The paper also presents a two-sector, open economy model of capital accumulation, where the friction mechanism is combined with standard assumptions about household preferences and production technology, which generates plausible dynamics of macroeconomic variables.

JEL Classification Numbers: F41, F43

Keywords: Real exchange rate, capital inflows, capital accumulation, capital mobility Author's E-Mail Address: vklyuev@,imf.org

\footnotetext{
${ }^{1}$ I would like to thank Eric Clifton, Andrew Feltenstein, Saleh Nsouli, Sunil Sharma, and seminar participants at the IMF Institute for useful comments and suggestions.
} 


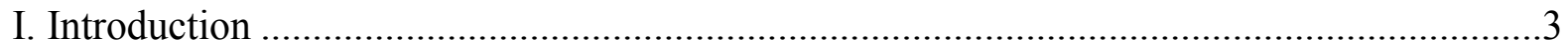

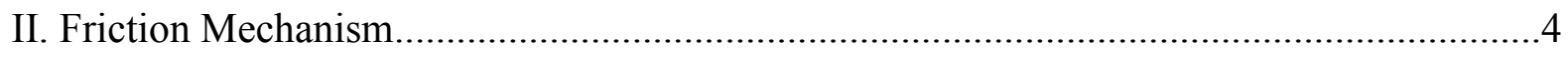

III. Model of Capital Accumulation with Imperfect Capital Mobility .................................6

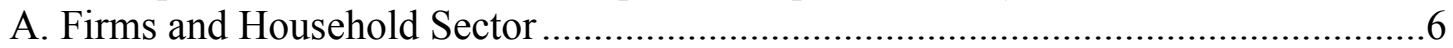

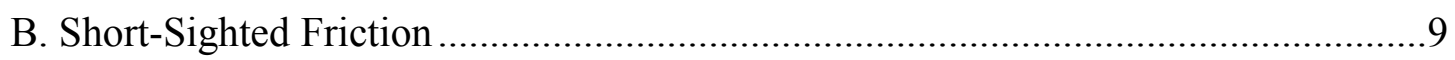

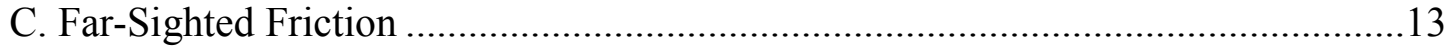

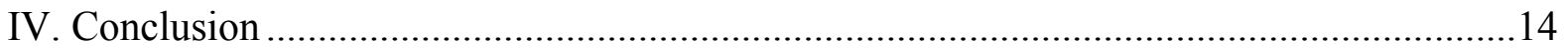

Figure

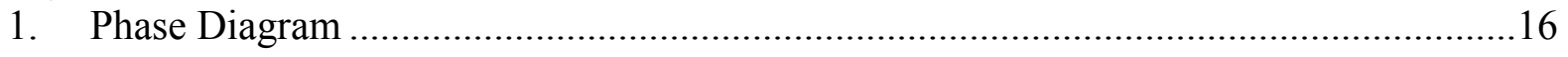

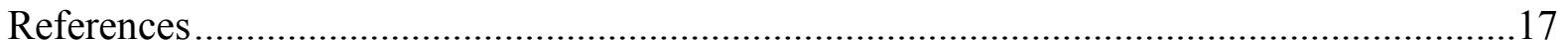




\section{INTRODUCTION}

Among the most important issues in international macroeconomics are those pertaining to the long-term dynamics of open economies. In a closed economy context, the Ramsey-Cass-Koopmans model provides a starting point for analysis of the issue, in a setting characterized by rational, forward-looking households and profit-maximizing firms, operating in a perfectly competitive environment with flexible prices. In the model, transitional dynamics are driven primarily by capital accumulation, while exogenous technological progress accounts for long-term growth.

As indicated in Barro and Sala-ì-Martin (1995), a straightforward extension of the Ramsey model to the open economy case under the assumption of perfect capital mobility eliminates all interesting dynamics. The literature has developed four principal ways of introducing dynamics into the behavior of an open economy. One approach is to adapt Blanchard's (1985) finite horizon model to an open economy setting. While this produces some transitional dynamics for the behavior of consumption, the capital stock and output still jump immediately to their steady states. One can make capital accumulation gradual by imposing constraints on the amount that can be borrowed abroad, like Cohen and Sachs (1986) or Barro, Mankiw, and Sala-ì-Martin (1995), introducing adjustment costs for investment (Brock, 1988), or assuming that capital goods are nontradable (Murphy, 1986).

While each of the these approaches breaks the link between being able to borrow in international credit markets and the ability to invest at an infinite rate, the domestic interest rate in these models either cannot be defined at all or equals the world interest rate throughout the course of transition. However, such immediate interest rate convergence has not been the experience of emerging economies. In addition, a constant interest rate (in terms of tradables) implies a constant marginal utility of consuming the tradable good. As a result, the consumption of tradables would remain constant over time, even as the economy accumulates capital, for a large class of utility functions that are additively separable in the tradable good. ${ }^{2}$

This paper introduces a realistic and tractable friction mechanism that would break interest rate parity and allow for nondegenerate dynamics in consumption, capital accumulation, and the adjustment of relative prices.

In our model, the cost of foreign borrowing increases with the amount of new borrowing in any given period. This reflects the fact that making a foreign loan requires expending resources that are in scarce supply, and the cost of those resources is going to be higher if the demand for them (the amount of new lending) increases. This friction is similar in spirit to adjustment cost, but rather than being the cost of installing a unit of capital equipment, it is a cost of "installing" a new loan. In reality this mechanism combines with other factors, such as investment adjustment costs and nontradability of certain capital goods, to slow down the

\footnotetext{
2 This, of course, is also true of models that feature only one consumption good, unless utility also depends in a nonseparable way on leisure.
} 
convergence process, but we focus on the capital market friction to highlight limits to capital mobility even in the absence of institutional restrictions and to generate realistic dynamics of the interest rate differential.

The paper is organized as follows. The next section introduces the friction mechanism, explaining the motivation, suggesting a specific formulation, and deriving implications. Section III embeds this mechanism in a two-sector, infinite horizon, open economy model of capital accumulation and growth. The model generates gradual convergence toward a steady state. Along the convergence path, the country accumulates capital and debt and increases consumption. The wage rate goes up over time, while the interest rate declines. The relative price of the more capital intensive good goes down. The section also explores the link between the intensity of the capital account friction and the speed of convergence, as well as the steady state values of the macroeconomic variables. The last section concludes.

\section{Friction MechanisM}

While it is frequently assumed in the international economics literature that competition among the banks of the advanced economies will drive the interest rate facing emerging market borrowers down to the "world interest rate," or to the cost of funds for the banks, this neglects the banks' cost of doing business. Moreover, it is safe to assume that the cost of doing business with a partner from an emerging economy is higher than that pertaining to a domestic client, given geographic remoteness, differences in language and business culture, scarcity of information, and uncertain enforcement.

We will assume that such costs increase as more people engage in these activities simultaneously because these activities draw on resources whose supply is not perfectly elastic, and the price of such resources will be bid up as more creditors use them. Of course, one can think of a countervailing effect - as more people engage in business with a particular country, specialized services will emerge (once the scale permits) that can make the above activities cheaper. More air routes will be opened, external assessments of creditworthiness will be developed, etc. In this paper we abstract from these developments. Infrastructure takes time to put in place, and for a given level of infrastructure, congestion should drive up the cost of doing business as more people do it. One can imagine that infrastructure develops in response to observed capital flows, so the cost of lending may be increasing in current flow but decreasing in the stock of debt. ${ }^{3}$ Our formulation has some of this learning-by-doing flavor, as we assume that rolling over an existing loan involves much less expense and, for the modeling purposes, we set the rollover cost to zero. It should be noted that the focus of this paper is on capital flows and interest rate movements driven by the demand side, so it

${ }^{3}$ A popular assumption in the literature is that the interest differential is an increasing function of the stock of debt (e.g., Montiel, 1999). This assumption is grounded in portfoliobalance considerations or in the notion that a higher stock of debt carries a higher probability of default. One can loosely argue that the reduction in the cost of doing business with the country and an increase in the risk premium as the country takes on more debt will offset one another. 
abstracts from the developments on the supply side of capital flows, such as changes in the world interest rate, establishment of a country's reputation and associated reduction in its risk premium, or development of infrastructure that facilitates foreign lending. Of course, having neglected these factors, we will not be able to explain all of the observed comovements of capital flows and domestic interest rates.

The role of the outside world in our model is that of a trading partner and the supplier of capital to the small economy. We do not provide full general equilibrium treatment of the outside world. Instead, we only model the banking sector in a partial equilibrium approach. Specifically, we assume that a certain resource has to be expended to extend a new loan. We will assume that this factor $x$ is resident in the outside world, so that we do not have to track it in the small economy. The amount of factor $x$ needed is proportional to the size of the loan, so

$x=\vartheta f$

for an individual lender, and

$X=\vartheta F$

in the aggregate, where $F$ is the total flow of capital into the country.

The supply of factor $X$ is proportional to its price:

$X=\xi P$.

Hence, the cost to an individual lender of lending one dollar to the country equals

$\vartheta P=\vartheta \frac{X}{\xi}=\frac{\vartheta^{2}}{\xi} F \equiv b F, \quad b=\frac{\vartheta^{2}}{\xi}>0$.

Thus the cost of bringing a new unit of capital into the country turns out to be $b F(t)$, where $F(t)$ is the total net flow of foreign capital at time $t$ and $b$ is a positive constant. Competition among foreign investors will ensure equality between the cost lending one dollar and the present discounted value of future revenues (i.e., interest payments), where the discount rate $\rho$ is the cost of funds, or the interest rate prevailing in the advanced economies (henceforth referred to as the "world interest rate"):

$1+b F(t)=\int_{t}^{\infty} r(s) e^{-\rho(s-t)} d s$

This condition implies the following differential equation: 
$r-\rho=b(\rho F-\dot{F}){ }^{4}$

One might argue that this derivation relies on too much foresight on the part of foreign investors and on their determination to keep their money in the economy once they get in. In addition, if this differential equation complements a model of the economy that is already complicated, the resulting system may be too complex to solve. As a shortcut, we suggest a simpler setup, where investors make only short-term loans and do not look beyond that horizon. Then the difference between the interest rate $r$ that they charge and their cost of funds $\rho$ will be the ratio of the marginal cost of new lending $b F$ to the loan maturity. In this formulation

$r-\rho=B F$,

where $B$ is the ratio of $b$ to the loan maturity.

\section{Model of CApital ACCUMUlation with Imperfect Capital Mobility}

In this section we give an example of incorporating the friction mechanism into a two-sector, open economy growth model. After presenting the model, we combine it with the capital market friction (first in the short-sighted, and then in the far-sighted version), derive the properties of the steady state and the transition path, and analyze some comparative statics.

\section{A. Firms and Household Sector}

The model features infinitely lived optimizing consumers and two productive sectors, tradables and nontradables. Tradables, which are the numeraire good, are produced combining capital and labor in a neoclassical constant returns-to-scale production function:

$$
Q_{T}=F\left(K, L_{T}\right)=L_{T} f(k), \quad k \equiv \frac{K}{L_{T}}
$$

Profit maximization requires

$f^{\prime}(k)=r_{K}$

$f(k)-k f^{\prime}(k)=w$,

where $r_{K}$ is the rental rate of capital and $w$ is the wage rate.

\footnotetext{
${ }^{4}$ This equation can also be derived by perturbation argument, comparing the benefits of lending a marginal dollar to an emerging market borrower earlier (earning the interest premium for a longer period) and the benefits of getting into the market later (postponing the expense and paying a lower cost if $F$ declines over time).
} 
Nontradables are produced using only labor according to a linear technology:

$Q_{N}=L_{N}$.

This assumption captures (in the extreme form) the notion that the production of nontradables is less capital intensive than the production of tradables. This is an assumption that is frequently made in the literature (e.g., Fischer and Frenkel, 1974), although it has its critics (e.g., Flemming, 1982). Obstfeld and Rogoff (1996, p. 209) state as an empirical regularity that traded goods tend to be at least as capital intensive as nontraded goods. In addition, equilibrium real appreciation (the Balassa-Samuelson effect) has been shown to be an important feature of emerging economies (Rogoff, 1996), and explaining it by capital accumulation and differential capital intensity of the tradable and nontradable sectors seems intellectually more satisfying than simply assigning different rates of total factor productivity growth to the two sectors. ${ }^{5}$

The zero profit condition in the nontradable sector implies

$p_{N}=w$.

Hence, the wage rate in this simple model also plays the role of the real exchange rate, defined as the price of nontradables in terms of tradables. Both tradables and nontradables are used for consumption, but capital is assumed to be made of tradable good, so the price of one unit of capital is one. ${ }^{6}$ Households maximize the present discounted value of the logarithmic Cobb-Douglas instantaneous utility function:

$U=\int_{0}^{\infty}\left(\alpha \log c_{T}+(1-\alpha) \log c_{N}\right) e^{-\rho t} d t$.

Following the standard practice, the rate of time discounting equals the world interest rate.

\footnotetext{
${ }^{5}$ Kravis and Lipsey (1983) and Bhagwatti (1984) were among the first to suggest that higher exchange rate-adjusted price levels in richer countries can be explained by their higher capital-labor ratios.

${ }^{6}$ Brock and Turnovsky (1994) note that models which assume investment goods to be traded have been criticized, as have been models which make the opposite assumption. Their solution is to introduce two kinds of capital, one tradable and one nontradable. While realistic, this approach would add another state variable to the model and greatly complicate the solution. Having to choose in the absence of general consensus, we make the assumption that strikes us as more plausible and allows to highlight the effect of capital mobility on the speed of adjustment process. Making nontradable capital essential for production would not overturn our results, it would just slow down convergence.
} 
Households can hold their wealth in the form of capital or domestic bond denominated in the units of tradable goods. Households view both types of wealth as perfect substitutes, so the rates of return on them should be equalized, which requires an equality between the rental rate of capital, corrected for depreciation, and the interest rate on the bond:

$r_{K}-\delta=r$

Households can also borrow abroad at the interest rate $r$. Since all the agents are identical, in equilibrium no bonds will be issued, and the net asset position $A$ of a household will equal the difference between its holdings of capital $K$ and external indebtedness $D$ :

$A=K-D$

The households provide capital services to the market. They also supply inelastically $L$ units of labor. The budget constraint of a household takes the following form:

$\dot{A}=r A+w L-c_{T}-w c_{N}$.

The agents maximize $U$ subject to their budget constraint and the initial holding of capital, taking the time paths of $r$ and $w$ as given. Optimization yields an intratemporal condition

$$
\frac{c_{T}}{w c_{N}}=\frac{\alpha}{1-\alpha}
$$

and an intertemporal Euler equation

$$
\frac{\dot{c}_{T}}{c_{T}}=r-\rho .
$$

It is convenient to introduce the total value of consumption basket in terms of tradables:

$c=c_{T}+w c_{N}$.

Obviously, $c_{T}=\alpha c$ and $w c_{N}=(1-\alpha) c$.

Capital intensity in the tradable sector, capital stock, and consumption expenditure are linked through a relationship that comes from the definition of $k$ and the market-clearing conditions for labor and for nontradables:

$$
k=\frac{K}{L_{T}}=\frac{K}{L-L_{N}}=\frac{K}{L-Q_{N}}=\frac{K}{L-c_{N}}=\frac{K}{L-\frac{(1-\alpha) c}{w(k)}}
$$


It is straightforward to show that this equation has a unique solution, so it defines $k$ as an implicit function of $K$ and $c$, increasing in both variables.

$$
\begin{aligned}
& k=k\left(\begin{array}{c}
K, c \\
+
\end{array}\right) \\
& \frac{\partial k}{\partial K}=\frac{1}{L-(1-\alpha) \frac{c}{w}-(1-\alpha) \frac{c k^{2}}{w^{2}} f^{\prime \prime}(k)}=\frac{1}{L_{T}-\frac{k^{2}}{w} f^{\prime \prime}(k) L_{N}}>0 \\
& \frac{\partial k}{\partial c}=\frac{(1-\alpha) \frac{k}{w}}{L-(1-\alpha) \frac{c}{w}-(1-\alpha) \frac{c k^{2}}{w^{2}} f^{\prime \prime}(k)}=\frac{(1-\alpha) \frac{k}{w}}{L_{T}-\frac{k^{2}}{w} f^{\prime \prime}(k) L_{N}}>0 .
\end{aligned}
$$

\section{B. Short-Sighted Friction}

We can now collect these fairly standard equations and combine them with the short-sighted capital friction equation and the obvious link between the stock of debt and the flow of net lending. The evolution of the economy will be described by the following system of equations:

$$
\begin{aligned}
& B F=r-\rho \\
& \frac{\dot{c}}{c}=r-\rho \\
& \dot{D}=F \\
& \dot{K}-\dot{D}=r K-r D+w L-c \\
& f^{\prime}(k)=r+\delta \\
& f(k)-k f^{\prime}(k)=w \\
& k=\frac{K}{L-\frac{(1-\alpha) c}{w}}
\end{aligned}
$$

The first three equations imply that $\frac{\dot{c}}{c}=B \dot{D}$, which means that $(\ln c-B D)$ is a constant.

Assuming that the economy opens up to capital inflows at time zero, so that $D(0)=0$, we can write $D=\frac{1}{B} \ln \left(\frac{c}{c_{0}}\right)$. With this substitution, we reduce our system to two differential equations:

$$
\begin{aligned}
& \frac{\dot{c}}{c}=r(k)-\rho \\
& \dot{K}=\frac{r(k)-\rho}{B}+r(k) K-r(k) \frac{1}{B} \ln \left(\frac{c}{c_{0}}\right)+w(k) L-c,
\end{aligned}
$$


with $k=k(K, c)$ as indicated above.

The behavior of this system can be analyzed with the help of a phase diagram. The system will be in steady state when both right-hand side expressions equal zero. The locus of the points $\dot{c}=0$ is the downward sloping straight line along which $f^{\prime}(k(K, c))=\rho+\delta .^{7}$ Below and to the left of that line, capital intensity is below its steady state value, the domestic interest rate is higher than the world rate, and consumption expenditure is increasing. Above and to the right of that line, consumption expenditure declines over time.

The locus of the points such that $\dot{K}=0$ is more difficult to establish. The slope of this line equals

$$
\left.\frac{d c}{d K}\right|_{\dot{K}=0}=\frac{r-f^{\prime \prime} \frac{\partial k}{\partial K}\left[k L_{N}+\frac{1}{B}\left(\ln \frac{c}{c_{0}}-1\right)\right]}{1+\frac{r}{B c}+f^{\prime \prime} \frac{\partial k}{\partial c}\left[k L_{N}+\frac{1}{B}\left(\ln \frac{c}{c_{0}}-1\right)\right]} .
$$

In case of zero capital mobility $(B=\infty)$, the slope is positive:

$$
\left.\frac{d c}{d K}\right|_{\substack{K=0 \\ b=\infty}}=\frac{r-k f^{\prime \prime} L_{N} \frac{\partial k}{\partial K}}{1+k f^{\prime \prime} L_{N} \frac{\partial k}{\partial c}}=\frac{\left(r-k f^{\prime \prime} L_{N} \frac{\partial k}{\partial K}\right)\left(L_{T}-\frac{k^{2}}{w} f^{\prime \prime} L_{N}\right)}{L_{T}-\alpha \frac{k^{2}}{w} f^{\prime \prime} L_{N}} .
$$

The stock of capital is increasing to the right of the line $\dot{K}=0$ and decreasing to its left. The phase diagram is depicted in Figure 1.

With higher capital mobility, $b$ is smaller, and the consumption profile is smoother. For low enough $B$, the term $\frac{1}{B}\left(\ln \frac{c}{c_{0}}-1\right)$ becomes large and negative and comes to dominate the other terms. The numerator turns negative, so the line will be downward sloping. Still, as long as $B$ is positive, the expression will never reach its limit equal to $\left(-\frac{\partial k}{\partial K} / \frac{\partial k}{\partial c}\right)$, so the line $\dot{K}=0$ is always less downward sloping (if at all) than the line $\dot{c}=0$. Hence, the system

${ }^{7}$ The slope of this line equals $\left.\frac{d c}{d K}\right|_{\dot{c}=0}=-\frac{\partial k}{\partial K} / \frac{\partial k}{\partial c}=-\frac{w\left(k^{*}\right)}{(1-\alpha) k^{*}}$, where $k^{*}$ is the steady state capital intensity in tradables, satisfying the condition $f^{\prime}\left(k^{*}\right)=\rho+\delta$. 
possesses a saddle point equilibrium. Starting from the point where $K$ equals the initial stock of capital, the system will evolve along the stable arm and converge over time to the steady state.

One can also establish the saddle path dynamics of the system by linearizing it around the steady state:

$$
\left.\frac{d}{d t}\left[\begin{array}{c}
c \\
K
\end{array}\right] \approx\left[\begin{array}{cc}
c^{*} f^{\prime \prime}\left(k^{*}\right) \frac{\partial k}{\partial c} & c^{*} f^{\prime \prime}\left(k^{*}\right) \frac{\partial k}{\partial K} \\
-1-\frac{\rho}{B c^{*}}- \\
-f^{\prime \prime}\left(k^{*}\right) \frac{\partial k}{\partial c}\left[k^{*} L_{N}^{*}+\frac{1}{B}\left(\ln \left(\frac{c^{*}}{c_{0}}\right)-1\right)\right]
\end{array}\right] f^{\prime \prime}\left(k^{*}\right) \frac{\partial k}{\partial c}\left[k^{*} L_{N}^{*}+\frac{1}{B}\left(\ln \left(\frac{c^{*}}{c_{0}}\right)-1\right)\right]\right]\left[\begin{array}{c}
c-c^{*} \\
K-K^{*}
\end{array}\right],
$$

and confirming that the determinant of the matrix, which equals

$c^{*} f^{\prime \prime}\left(k^{*}\right)\left[\frac{\partial k}{\partial K}+\rho \frac{\partial k}{\partial c}+\frac{\rho}{B c^{*}} \frac{\partial k}{\partial K}\right]$, is negative.

Regarding the solution, it should be noted that in the system of two differential equations $c_{0}$ was an unknown parameter. If it is chosen arbitrarily, there is no guarantee that the stable arm of the saddle path will pass through the point $\left(K_{0}, c_{0}\right)$. If the phase diagram is used to find the solution (e.g., implicitly in numerical simulations), the consistent value of $c_{0}$ could be found by trial and error. In this paper we are not concerned with finding the exact solution, we are only trying to establish some of its properties.

If the economy starts with a capital stock that is lower than the steady state value (emerging economy situation), then the dynamics of the system on its path toward the steady state will look as follows: the capital stock will rise, both in per capita terms and per worker in the tradable sector; the interest rate will go down; the wage rate will increase; the real exchange rate will appreciate. Consumption of tradables and the value of total consumption in terms of tradables will go up.

How does the value of parameter $B$ - the extent of the friction in the capital market —affect the evolution of the system? Qualitatively, the behavior of the price and quantity variables will be as described in the previous paragraph for any degree of friction, including a completely closed capital account, though excluding the case of no friction at all $(B=0){ }^{8}$ What will be affected is the speed of transition. It is intuitively clear that easier access to

\footnotetext{
${ }^{8}$ In that case, transition is instantaneous. If a growing economy with a closed capital account opens up to frictionless capital inflows, the quantity and price variables will jump immediately to their steady state values in the direction in which they would evolve more gradually in a world with friction.
} 
foreign financing should speed up capital accumulation. First of all, if the domestic rate of return on capital, $f^{\prime}(k)-\delta$, is higher than the external cost of funds $\rho$, the country will find it advantageous to borrow until the interest rate on external loans, $\rho+B F$, is equalized with the domestic rate of return. Second, while in principle the residents of the economy could reduce their saving by an amount that exceeds the inflow of foreign finance, and hence accumulate capital at a slower pace than in the closed economy case, they will not find it optimal to do so. Taking up more debt to increase present consumption means lower consumption in the future. According to the Euler equation, a flatter consumption profile would have to be induced by lower interest rates, that is, by higher capital-labor ratios. Hence, a scenario in which capital accumulation is slower but consumption is higher than in the closed economy benchmark is incompatible with the Euler equation.

Less friction would result in a smaller wedge between the domestic and the world interest rate, which implies a flatter consumption profile. Taking the time paths of the wage rate and the interest rate as exogenous, one can show that the solution to the consumer problem can be written as

$$
c(t)=c_{0} \exp \left[\int_{0}^{t}(r(s)-\rho) d s\right]
$$

where

$$
c_{0}=\rho\left[K_{0}+L \int_{0}^{\infty} w(t) e^{-\int_{0}^{t} r(s) d s} d t\right]
$$

In an economy that starts from a capital-labor ratio that is lower than the steady state value, openness to capital inflows will lead to higher wages and lower interest rates at any point in time relative to the closed economy benchmark. Therefore, initial consumption will be higher.

Steady state consumption equals

$$
c^{*}=\rho\left(K^{*}-D^{*}\right)+w^{*} L .
$$

Using the equality $K^{*}=k^{*}\left(L-\frac{(1-\alpha) c^{*}}{w^{*}}\right)$, we can find a relationship between the steady state consumption and debt, as well as between capital stock and debt:

$$
c^{*}=\frac{\rho\left(k^{*} L-D^{*}\right)+w^{*} L}{1+(1-\alpha) \frac{\rho k^{*}}{w^{*}}} \quad K^{*}=k \frac{\alpha w^{*} L+(1-\alpha) \rho D^{*}}{w^{*}+(1-\alpha) \rho k^{*}} .
$$


Easier access to capital markets (lower $B$ ) will induce the country to take on more debt. As a result, the country will be able to afford less consumption in the steady state. At the same time, the stock of capital and the output of tradables will be higher, since lower consumption means lower demand for nontradables, ${ }^{9}$ so that more workers will be employed in the tradable sector. The difference between the greater production and the smaller consumption of tradables equals extra interest payments on the external debt.

\section{Far-Sighted Friction}

Now we introduce the more far-sighted behavior of foreign investors, where they recognize that once they have made initial investment and incurred cost $b F(t)$, it will be profitable for them to stay in that market, since rollover is costless while the interest rate $r$ is higher than the cost of funds $\rho$. They will, therefore, compare the cost of investing one dollar with the present discounted value of the stream of interest payments, rather than looking at the differential between the instantaneous interest rates in the emerging and mature economies. As shown above, this reasoning will give rise to the following condition: $r-\rho=b(\rho F-\dot{F})$. It can be rewritten as

$\dot{F}=\rho F-\frac{r-\rho}{b}$.

This condition will replace the simpler equation $B F=r-\rho$ in our previous model. The rest of the system remains the same.

To solve the model, we first note the following dynamic relationship:

$\dot{F}=\rho \dot{D}-\frac{1}{b}\left(\frac{\dot{c}}{c}\right)$

This implies that $\left(F-\rho D+\frac{1}{b} \ln c\right)$ must be constant over time. Recognizing that in the steady state the capital flows will cease and $D$ will reach its steady state value, we can write $D=D^{*}+\frac{F}{\rho}+\frac{1}{b \rho} \ln \left(\frac{c}{c^{*}}\right)$

Now the system reduces to three differential equations:

$\dot{c}=(r-\rho) c$

${ }^{9}$ Keep in mind that the steady state values of the interest rate, capital intensity in the tradable sector, the wage rate, and the relative price of nontradables do not depend on the value of $B$. 
$\dot{F}=\rho F-\frac{r-\rho}{b}$
$\dot{K}=F+r K+w L-c-r\left(D^{*}+\frac{F}{\rho}+\frac{1}{b \rho} \ln \left(\frac{c}{c^{*}}\right)\right)$,

with $r$ and $w$ functions of $k=k(K, c)$. Linearizing the system around the steady state, we obtain

$$
\begin{aligned}
& \dot{c}=c^{*} f^{\prime \prime} \frac{\partial k}{\partial c}\left(c-c^{*}\right)+c^{*} f^{\prime \prime} \frac{\partial k}{\partial K}\left(K-K^{*}\right) \\
& \dot{K}=-\left[1+\frac{1}{b c^{*}}+\left(K^{*} \frac{L_{N}^{*}}{L_{T}^{*}}+D^{*}\right) f^{\prime \prime} \frac{\partial k}{\partial c}\right]\left(c-c^{*}\right)+\left[\rho-\left(K^{*} \frac{L_{N}^{*}}{L_{T}^{*}}+D^{*}\right) f^{\prime \prime} \frac{\partial k}{\partial K}\right]\left(K-K^{*}\right) \\
& \dot{F}=-\frac{f^{\prime \prime}}{b} \frac{\partial k}{\partial c}\left(c-c^{*}\right)-\frac{f^{\prime \prime}}{b} \frac{\partial k}{\partial K}\left(K-K^{*}\right)+\rho F .
\end{aligned}
$$

As one can see, in the vicinity of the steady state the laws of motion for $c$ and $K$ do not depend on $F,{ }^{10}$ so this subsystem of two equations in two unknowns can be solved separately. The determinant of the subsystem equals $c^{*} f^{\prime \prime}\left(k^{*}\right)\left[\left(1+\frac{1}{b c^{*}}\right) \frac{\partial k}{\partial K}+\rho \frac{\partial k}{\partial c}\right]$, which is negative. Hence, again, the model exhibits saddle path stability. Along the saddle path $k, K$, $w$, and $D$ go up, while $r$ and $F$ go down, with $r$ converging to the world interest rate $\rho$ and $F$ declining to zero.

The comparative statics with respect to the magnitude of the capital market friction are similar to those elaborated in the previous subsection. Easier access to foreign capital will accelerate the transition process and lead the country to take on more debt, which will result in lower consumption and higher capital stock in the steady state. The steady state values of the capital-labor ratio in the production of tradables, the wage rate, the real exchange rate, and the interest rate are not affected.

\section{CONCLUSION}

This paper introduces an innovative capital market friction mechanism that breaks the parity between domestic and external interest rates in an open economy setting and helps generate a plausible evolution of important macroeconomic variables. The mechanism, derived from microfoundations, is such that the cost of contracting a new loan is proportional to net capital inflows, while rollover is free. This friction is similar in spirit to the adjustment cost of

${ }^{10}$ In the original system, $F$ does not enter the equation for $\dot{c}$. It enters the equation for $\dot{K}$ in the form $F \frac{\rho-r}{\rho}$, which is of second order in the vicinity of the steady state. 
investment, except that we have a cost of "installing" a new loan rather than a piece of equipment. Unlike the portfolio balance or default risk models, the interest rate differential is related to the flow of new external financing, not to the stock of debt. An attractive feature of this formulation is that as an emerging country matures and becomes more like advanced economies, the interest rate premium that it pays on its external debt declines rather than going up as it would if the premium were related to the stock of debt.

As an illustration, we embed the friction mechanism in a two-sector open economy growth model, show how the model can be solved, and discuss the properties of the steady state and the transitional dynamics. In this setting we can consider the effect of changing the degree of capital mobility, with easier access to capital leading to faster capital accumulation and convergence toward the steady state, more rapid debt accumulation, and, as a result, higher steady state stocks of capital and debt, but lower steady state consumption.

In the model, the tradable sector is assumed to be more capital intensive than the nontradable sector. As a consequence of this assumption, capital accumulation leads to faster labor productivity growth in the tradable sector and, therefore, to equilibrium real appreciation along the Balassa-Samuelson lines. The association of the Balassa-Samuelson effect with capital accumulation is a relatively new feature of our approach. Traditionally, real appreciation is assumed to arise as a result of an exogenously given total factor productivity growth differential between the tradable and nontradable sectors (e.g., Obstfeld and Rogoff, 1996, pp. 210-12). ${ }^{11}$ Recent empirical research (Lee and Tang, 2003) shows that real exchange rate movements are linked much more robustly to labor productivity differentials (such as would arise in our formulation) than to total factor productivity differentials.

While the particular mechanism used to motivate and derive the friction equations may be narrow, one can think of other factors than would lead to the actual expense or perceived risk of lending to an emerging market borrower increasing with the amount of net lending. We believe that our formulation of the capital market friction equations combines the advantages of plausibility and tractability. It can be used in a variety of open economy models where nondegenerate dynamics of interest rates and other macroeconomic variables are essential for the analysis. In particular, the model presented in this paper could be extended to incorporate money, to analyze the effects of an anticipated capital account opening in the future, or to study the implications of different capital intensities in the tradable and nontradable sectors for the evolution of the real exchange rate.

${ }^{11}$ Brock (1994) is a rare exception. In his model, capital is nontraded and the domestic interest rate equals the exogenously given world interest rate. Brock's principal focus is on a switch from a low capital-intensity to a high capital-intensity technique in manufacturing. Lipschitz, Lane, and Mourmouras (2002) mention a possibility of real appreciation resulting from capital accumulation in the tradable sector, but they provide no formal treatment of the issue. 
Figure 1. Phase Diagram

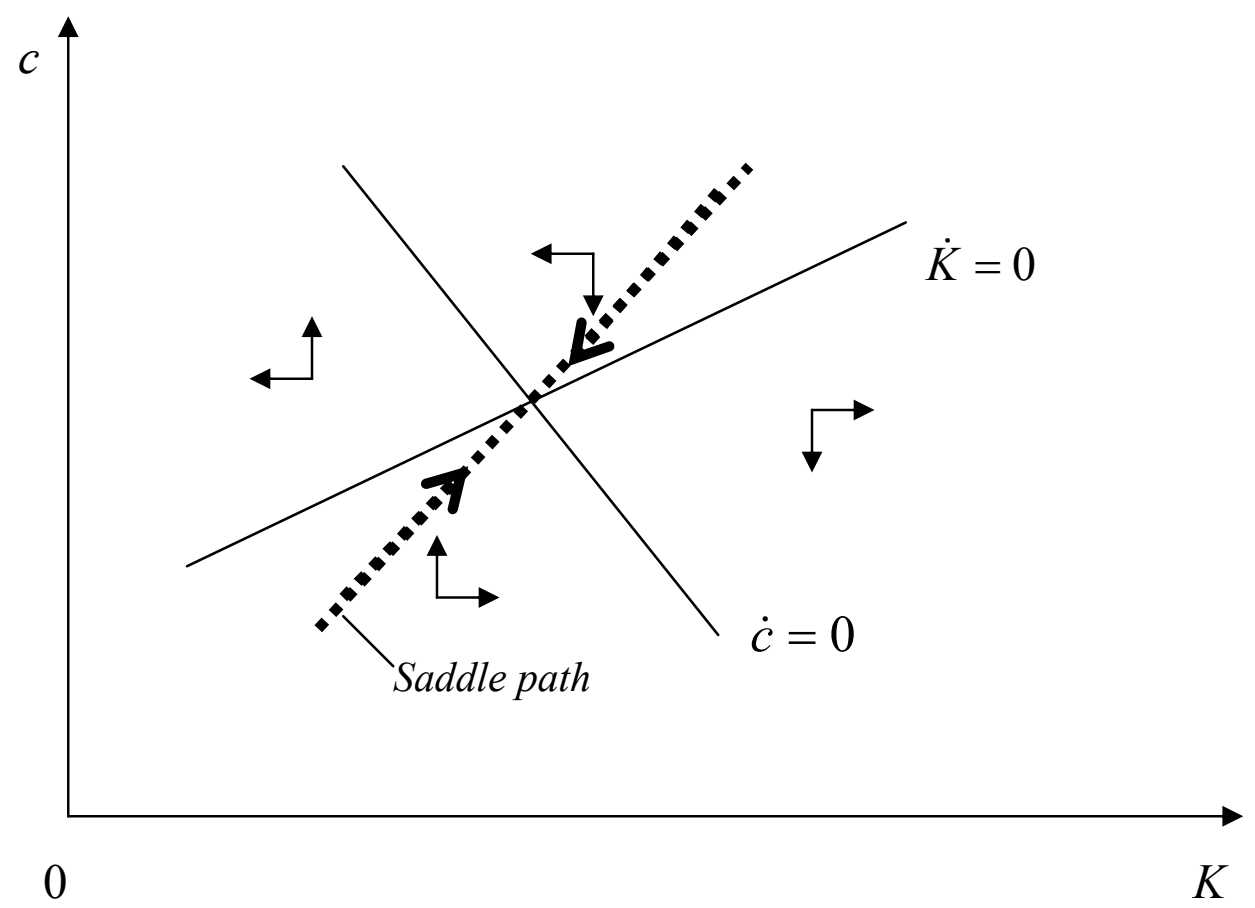




\section{REFERENCES}

Barro, Robert J., and Xavier Sala-ì-Martin, 1995, Economic Growth (New York: McGraw-Hill).

Barro, Robert J., N. Gregory Mankiw, and Xavier Sala-ì-Martin, 1995, “Capital Mobility in Neoclassical Models of Growth," American Economic Review, Vol. 85, pp. 103-15.

Bhagwati, Jagdish, 1984, "Why Are Services Cheaper in Poor Countries?” Economic Journal, Vol. 94, pp. 279-86.

Blanchard, Olivier, 1985, "Debt, Deficits, and Finite Horizons," Journal of Political Economy, Vol. 93, pp. 223-47.

Brock, Philip L., 1988, "Investment, the Current Account, and the Relative Price of NonTraded Goods in a Small Open Economy," Journal of International Economics, Vol. 24, pp. 235-53.

_ Dynamics of the Krueger-Deardorff-Leamer Model," Review of International Economics, Vol. 2, pp. 268-83.

and Stephen J. Turnovsky, 1994, "The Dependent-Economy Model with Both Traded and Nontraded Capital Goods," Review of International Economics, Vol. 2, pp. 306-25.

Cohen, Daniel, and Jeffrey Sachs, 1986, "Growth and External Debt under Risk of Debt Repudiation," European Economic Review, Vol. 30, pp. 526-60.

Fischer, Stanley, and Jacob A. Frenkel, 1974, "Economic Growth and Stages of the Balance of Payments," in Trade, Stability and Macroeconomics: Essays in Honor of Lloyd A. Metzler, ed. by G. Horwich and Paul A. Samuelson (New York: Academic Press).

Flemming, J.S., 1982, "Comment on J.P. Neary and D.D. Purvis, 'Sectoral Shocks in a Dependent Economy: Long-Run Adjustment and Short-Run Accommodation,", Scandinavian Journal of Political Economy, Vol. 84, pp. 255-57.

Kravis, Irving B., and Robert E. Lipsey, 1983, “Toward an Explanation of National Price Levels," Princeton Studies in International Finance, 52 (Princeton: International Finance Section, Department of Economics, Princeton University).

Lee, Jaewoo, and Man-Keung Tang, 2003, "Does Productivity Growth Lead to Appreciation of the Real Exchange Rate?” IMF Working Paper 03/154 (Washington: International Monetary Fund). 
Lipschitz, Leslie, Timothy Lane, and Alex Mourmouras, 2002, "Capital Flows to Transition Economies: Master or Servant?” IMF Working Paper 02/11 (Washington: International Monetary Fund).

Montiel, Peter J., 1999, "Determinants of the Long-Run Equilibrium Real Exchange Rate: An Analytical Model," in Exchange Rate Misalignment: Concepts and Measurement for Developing Countries, ed. by Lawrence E. Hinkle and Peter J. Montiel (New York: Oxford University Press).

Murphy, Robert G., 1986, "Productivity Shocks, Non-Traded Goods, and Optimal Capital Accumulation," European Economic Review, Vol. 30, pp. 1081-95.

Obstfeld, Maurice, and Kenneth Rogoff, 1996, Foundations of International Macroeconomics, (Cambridge, Massachusetts: MIT Press).

Rogoff, Kenneth, 1996, “The Purchasing Power Parity Puzzle," Journal of Economic Literature, Vol. 34, pp. 647-68. 